\title{
Empirical Study on Game Design for Reducing Smartphone Usage among Young Children
}

Nur Humairah Aini Mohd Fidzal, Sharifalillah Nordin, Norshahida Shaadan, and Nor Fazlin Mohd Ramli

To Link this Article: http://dx.doi.org/10.6007/IJARBSS/v11-i5/9923

DOI:10.6007/IJARBSS/v11-i5/9923

Received: 25 March 2021, Revised: 20 April 2021, Accepted: 07 May 2021

Published Online: 15 May 2021

In-Text Citation: (Fidzal et al., 2021)

To Cite this Article: Fidzal, N. H. A. M., Nordin, S., Shaadan, N., \& Ramli, N. F. M. (2021). Empirical Study on Game Design for Reducing Smartphone Usage among Young Children. International Journal of Academic Research in Business and Social Sciences, 11(5), 267-274.

Copyright: (C) 2021 The Author(s)

Published by Human Resource Management Academic Research Society (www.hrmars.com)

This article is published under the Creative Commons Attribution (CC BY 4.0) license. Anyone may reproduce, distribute, translate and create derivative works of this article (for both commercial and non-commercial purposes), subject to full attribution to the original publication and authors. The full terms of this license may be seen at: http://creativecommons.org/licences/by/4.0/legalcode

Vol. 11, No. 5, 2021, Pg. 267 - 274

Full Terms \& Conditions of access and use can be found at http://hrmars.com/index.php/pages/detail/publication-ethics 


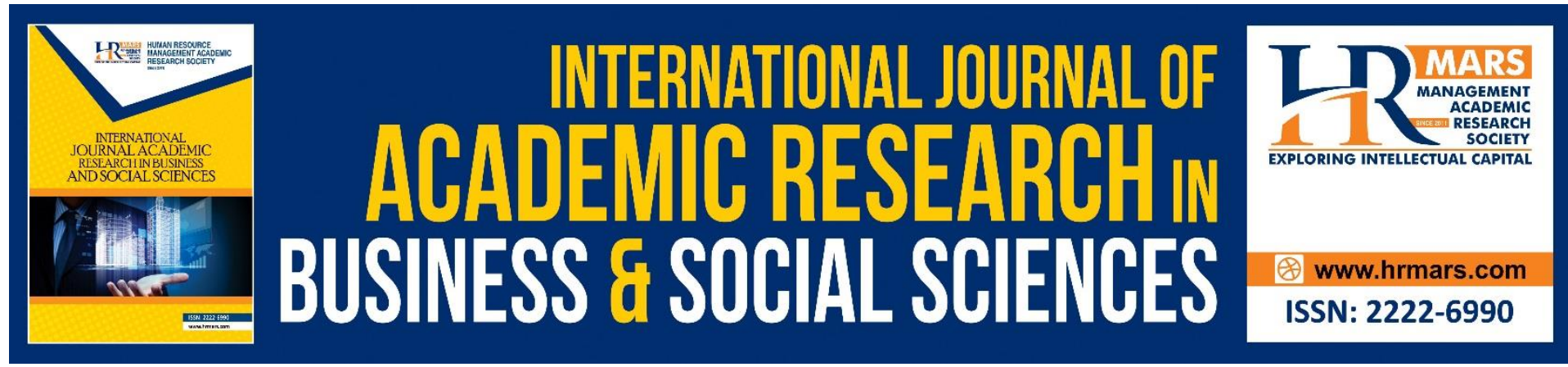

\title{
Empirical Study on Game Design for Reducing Smartphone Usage among Young Children
}

\author{
Nur Humairah Aini Mohd Fidzal ${ }^{1}$, Sharifalillah Nordin², \\ Norshahida Shaadan ${ }^{3}$, and Nor Fazlin Mohd Ramli ${ }^{4}$ \\ 1,2,3 Faculty of Computer and Mathematical Sciences, ${ }^{4}$ Akademi Pengajian Bahasa \\ Universiti Teknologi MARA (UiTM) Shah Alam, Selangor, Malaysia \\ Email: nurhumairahaini@gmail.com, sharifa@tmsk.uitm.edu.my, \\ shahida@tmsk.uitm.edu.my, norfa707@uitm.edu.my
}

\begin{abstract}
Young children and teenagers are the internet generation that is called generation Z. They are more exposed to and keen to use digital devices especially smartphone. However, most of them tend to be addicted to these devices, which can adversely affect their mental health and well-being. An integrated approach should be of concern and vitally in needs to some extent at least reduce the negative impact of this smartphone addiction. Fortunately, this study is purposely conducted with the aim to identify suitable feature in developing a software as a medium that can reduce smartphone usage and thus prevent smartphone addiction. An empirical research was done through an online survey to identify the features of a game design to develop a computer application that can reduce smartphone usage. The study focuses on parents with children under 7 years of age and has a total of 253 respondents. Based on the findings, the main features that can be implemented to design the game for reducing smartphone usage among young children are strategy game and building block.
\end{abstract}

Keywords: Smartphone Usage, Smartphone Addiction, Empirical Study

\section{Introduction}

Nowadays, people are finding it is more and more difficult to stay away from technology as the world keeps moving forward. Furthermore, the Internet provides access to perform everyday tasks more efficiently such as online business and online transactions. People also use the Internet for entertainment and as a way to escape real life. Entertainment and escapism are the main attractions of going online. As Internet has become more easily accessible and affordable, users find themselves attached to their gadgets like the smartphone. However, the overuse of technology can lead to addiction and can affect the users' mental health (Kassiani et. al, 2018; Zochil et. al, 2015).

The term 'digital addicts' is used to describe people whose interaction with technology is excessive and who threaten to absorb their attention above all else and therefore has a negative effect on the well-being of the users (Vagela \& Pratiksinh, 2016). This is supported by Rugai et. al (2016) that stated that digital addiction is similar to other addictions that can 
affect mental health. There are many types of digital addiction, and the most prevalent is smartphone addiction (Nightingale, 2015; Gandolfi, 2010).

People tend to use their smartphones more frequently that it has become a crucial part of everyday activities. Statistics have shown that the average time spent on smartphones per day between 2011 and 2013 nearly doubled from 98.1 minutes in 2011 to 194.7 minutes in 2013 (Rapeepisarn, 2016). The smartphone is not only used by adults, but it is also used by children. In recent studies conducted by the UK Communications Office (2017), 21\% between the ages of three (3) and four (4) have their own tablets.

The smartphone helps us in our daily lives. However, if people are dependent on smartphone, it means they could eventually develop smartphone addiction. When a child is exposed to a gadget at a young age, there are many opportunities and tendencies for smartphone addiction. Even if it helps children gain additional knowledge, it still has a negative impact on their lives (Alghamdi, 2016). Hence, one of the ways to avoid addiction is to reduce smartphone usage.

While many advanced technologies that are being developed to access the Internet, some of the technologies have a tool that can help to reduce or prevent addiction (Souligna, 2017). A recent study of Cham et. al, (2019) stated that technology plays a key role in enhancing the well-being of online users and helps to prevent unhealthy usage behaviors. One of the approaches that are used in the technology is gamification and this approach was suggested to deal with smartphone addictions (Jiang et. al, 2015).

The objective of this paper is to find the appropriate features of game design for creating a computer application that can reduce smartphone use. Gamification strategies describe the use of elements of game design in a non-game context (Deterding et. al, 2011). By focusing on credibility and reward systems such as points or levels, these strategies can help to increase human motivation. Due to the software application's recent development, knowledge of how to create an appropriate application is still relevant. Hence, by using the online survey, the question focuses more on the element of the game that the children play in their everyday lives. This is essential because it must be implemented in the computer application.

The outline of this paper is it firstly discusses the existing application that is being analyzed. The purpose of this part is to find the common features that are being implemented in the application that can reduce usage. The next section of this paper presents the method used in this study. This is followed by the results of the online survey in the key finding and discussion section. This part shows the features that need to be implemented in the game design based on the survey. Finally, the last section presents the conclusion from the findings.

\section{Method}

This empirical research based on Figure 1 uses mixed-method approaches adapted from Creswell's (Creswell et. al, 2003) design framework. The mixed-method approach is a combination of quantitative and qualitative data. By using this method, an internet survey was used to collect data from respondents consisting of parents who have children under 7 years old.

This research framework consists of four phases of activities which are preliminary study, the pilot research, the actual study including the analysis and the last phase is conclusion. The following is the explanation about the process of Creswell's method depicted in Figure 1.

The preliminary study phase includes the process of exploring, discovering and finding relevant information. Several sources like articles, thesis, books, journals and trusted websites 
were used to provide all the information regarding the problem statement and literature review. The output of this phase is the problem statement of the research, the research objective, and scope of the research.

Next, the pilot research phase focuses on the process related to questionnaire designed which was based on the literature search and review on the related works. The appropriateness of the questionnaires was assessed by analyzing all the related works about the existing application that had been developed to reduce smartphone usage. The researcher created a set of questions from the literature review and have found the correct design for creating a computer application that can reduce smartphone use. The output of this phase is the analysis of the existing applications based on their features and their problems and the questions of online survey.

The third phase is the actual study and at this phase, the online survey was carried out by the researcher by using Google form. The online survey was distributed to parents who have children under the age of 7 . The online survey is distributed through social media platforms and WhatsApp to kindergarten schools across Shah Alam and Klang. The survey aims to define an acceptable design and features for the computer application. The online survey data analysis was then conducted at this stage using some statistical analysis.

The last phase is the conclusion that focused on the final research reports. All the findings are recorded by in one paper. The conclusion was made from the data collection. The outcome of this phase is the conclusion of this research and this paper's final report.

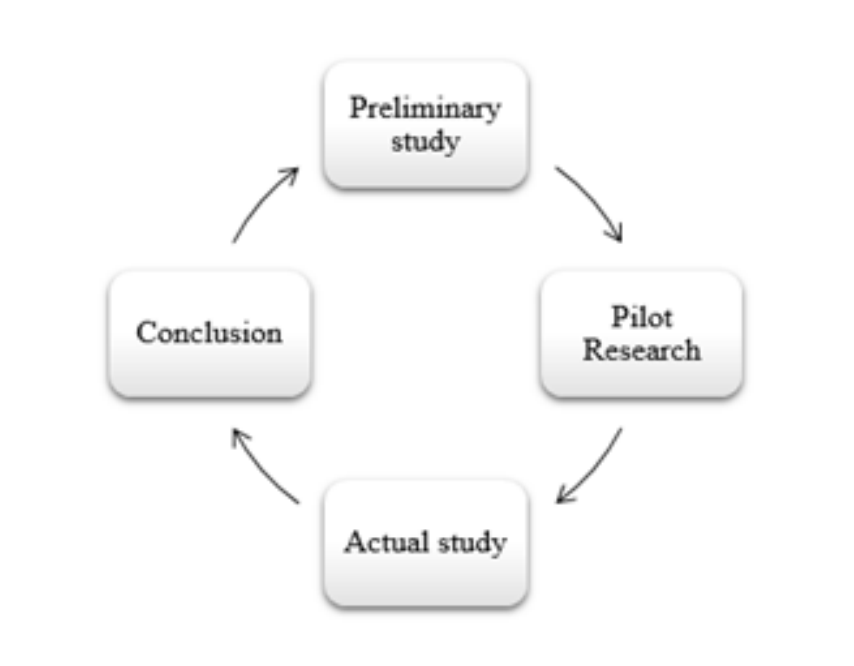

Fig.1: Methodology process

\section{Results and Discussion}

This study aims to find the suitable features of game design for creating a computer application that can reduce smartphone usage for kids. A total of 253 parents answered the questionnaire through Google form. The data analysis of the respondents have been made through Google form itself.

The first question is the purpose of using smartphone. The reason for this question is to define the main purpose of smartphone use for children. Therefore, the researcher can relate to the types of computer applications suitable for children, which can reduce the use of smartphones. 
From the results in Figure 2, it shows that the highest number is 104 (41.1\%) parents who select both play games and watch video as the main purpose of using a smartphone. Followed by, $103(40.7 \%)$ parents agree that the purpose of their children use the smartphone is for watching videos only. Twenty-seven (10.7\%) parents choose the purpose of using the smartphone for their children to play games only. On the other hand, 12 (4.7\%) parents select others as their choice, while another 7 (2.8\%) parents put none as their answer because their children do not use the smartphone.

From these results, many parents agree that the main purpose of their children using phone is to play games and watch videos. Therefore, the types of computer applications that are suitable for children are gamification as indicated by the highest percentage of the purpose using the smartphone.

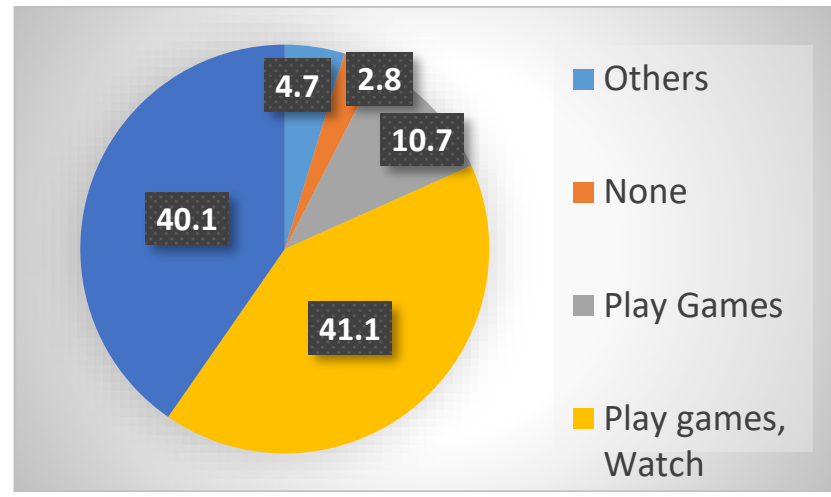

Fig.2: Purpose of using smartphone

For this question, the respondents need to identify the type of games their kids play, and the games are classified by their genre. The reason for this question is to find out what kind of games the kids are playing. It is important to know the types of games they play to be implemented in the computer application. This is indicated by the highest number of the purpose of using the smartphone,

Based on figure 2, the total number of parents who choose playing games as their purpose of using a smartphone is 131 (51.6\%). The 131 parents then need to identify the type of games that their children like to play. They can provide more than one answer.

After the categorization of the games, the results in figure 3 show that $36(14.2 \%)$ out of 131 parents state that the type of games that their children like to play is a strategy game. The second highest is action game which is $33(13 \%)$ followed by education game which is 32 $(12.6 \%)$. Another two types of game that the children like to play is cartoon which is $16(6.3 \%)$ and puzzle which is 1 (5.5\%). The remaining 122 (48.2\%) parents put none as their answer because their children do not play games on their smartphones.

Based on the results, the type of games that the children like to play is strategy game. It is the highest number in the data analysis. Therefore, the type of game design that the researcher needs to implement in the computer application is the strategy game. 


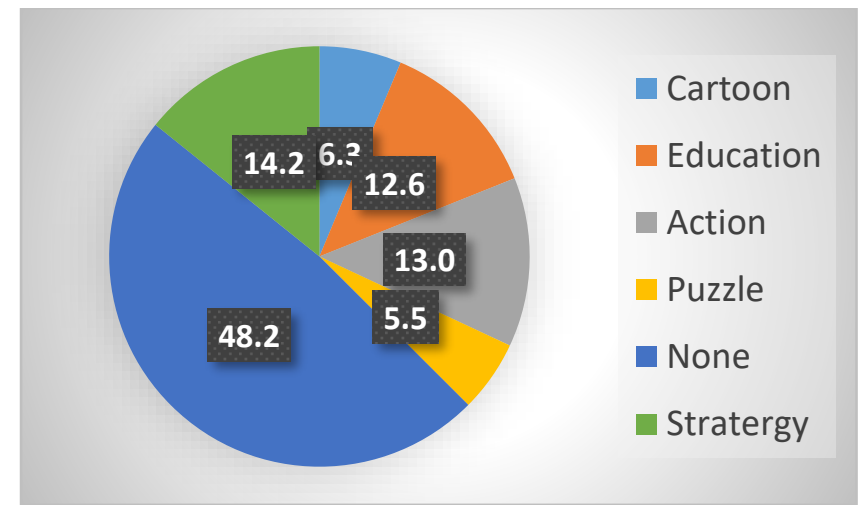

Fig.3: Types of game

After learning the game design genre for the computer application, the next important thing to know is the interest of the children. The reason for this question is to find out what can be implemented in the strategy game. There are 5 answers to this question and the respondents may choose more than one answer.

From the results in figure 4 , the highest percentage is building blocks which is $27.4 \%$. Next, $26.73 \%$ of parents choose their child's interest as playing with a doll or soft toys. This is followed by $16.7 \%$ parents from 253 choose puzzle as their child's interest. The next interest is playing with pets which is $14.8 \%$. The least number is planting trees which is $3.5 \%$. The last option is others which is $11.3 \%$.

Thus, the results portray that most children love to build blocks. The outcome of this question is similar to the game of genre strategy as building blocks are included in the category of strategy games.

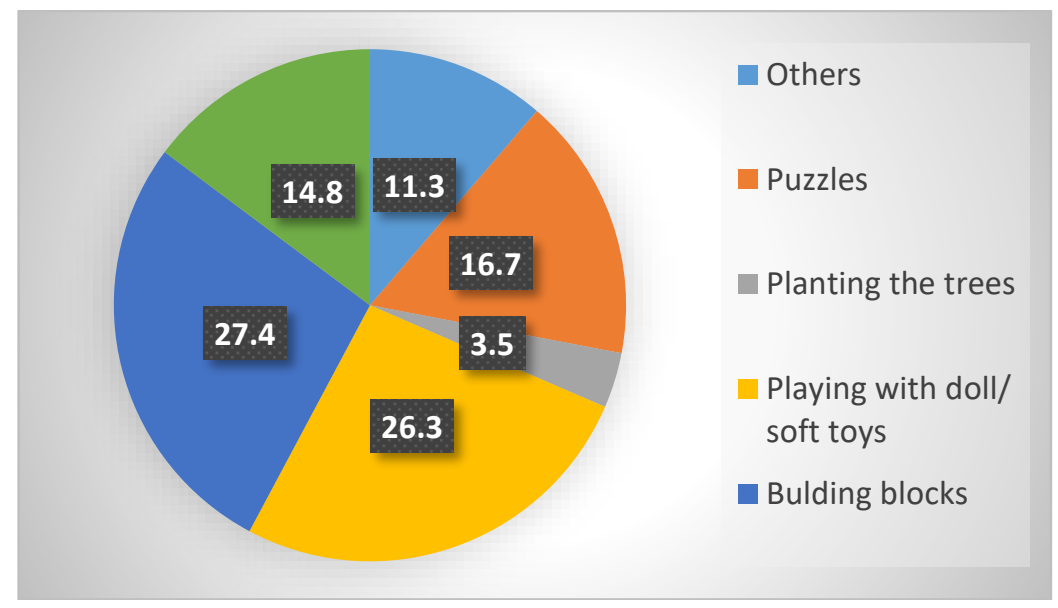

Fig. 4: Child Interest

Figure 5 illustrates that highest number for the children's interest is building blocks from 253 respondents. The number in the figure 5 is the total number of both genders which is a combination of males and females. This section shows and discusses the children's interest between the two genders. Therefore, the researcher can incorporate suitable features for both genders in the computer application.

From the results in figure 6, the highest percentage for female is playing with a doll or soft toys which is $31 \%$. Followed by, $21.5 \%$ of female interest is building blocks. Moreover, only $19 \%$ of parents from 253 choose puzzles as their children's interest. The next interest is playing with pets which is $16 \%$. The least number is planting the trees which is $4 \%$ females. 
For males, building blocks is the highest percentage which is $33.90 \%$. The second highest is playing with a doll or soft toys which is $21 \%$. Next, playing with pets and puzzles for males gain the same percentage which is $14 \%$. The least interest for males is planting trees which is $4 \%$.

Thus, it can be observed that the female interest is more towards doll or soft toys and the male interest is more towards building blocks. Therefore, the researcher can include both interests in the genre strategy game.

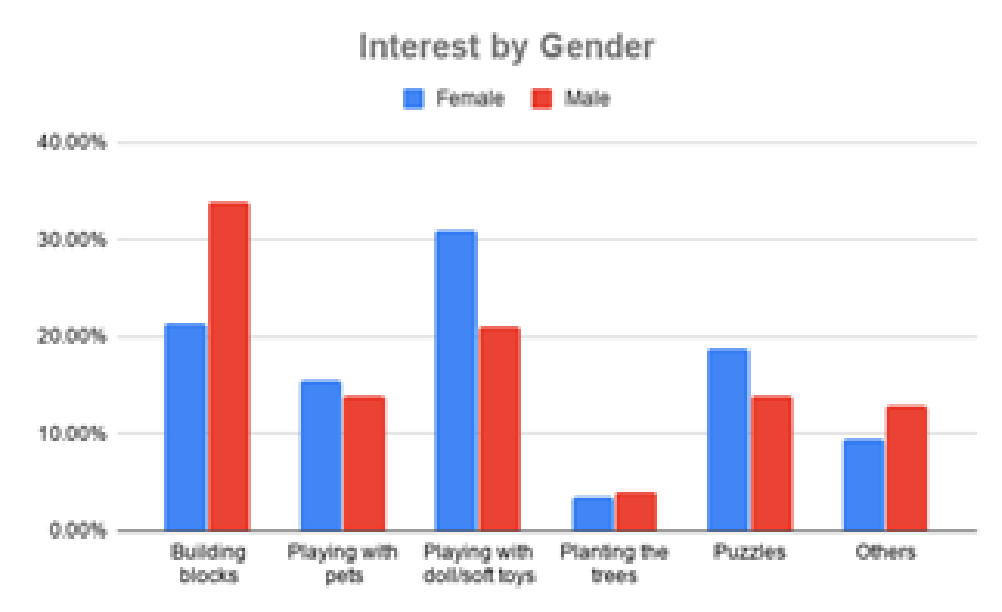

Fig. 5: Interest by Gender

\section{Conclusion}

In this study, we conducted empirical research through an online survey to identify the suitable features of game design for creating a computer application that can reduce smartphone usage among kids. After the survey was released online, 253 parents responded to the online survey. The online survey is distributed through social media platforms and WhatsApp to kindergarten schools across Shah Alam and Klang. There are few findings based on the survey's data collection that can help to develop a computer application.

Based on the finding, the main features are the type of games that needs to be incorporated into the game application. As this application adopts gamification technique, the type of game will be the main feature. Based on the data analysis of the study, the type of games that the children like to play is the strategy game. Therefore, the type of game design that the researcher needs to implement in the computer application is strategy game

The next finding is to investigate the interest of children so that can it can be implemented in the strategy game. The strategy game is a game that the users need to make decisions in the game. From the results they reveal that the highest number for both genders is building blocks. The outcome of this question is the same as the game of genre strategy as building blocks are included in the category of strategy games.

The last question of this study is to show the importance of this study. The analysis of the respondents' answers indicates that the parents' awareness of existing technologies that may help to reduce the use of smartphones is weak. This is because of only 61 out of 253 parents actually realize that the existing technology that can help to reduce smartphone usage. The research is therefore significant to show the value of this application to help parents become more conscious of smartphone usage among their children.

In conclusion, based on the findings, the main feature that needs to be implemented in the computer application is gamification and this approach already been suggested by the past 
researchers. In addition, we need to incorporate a reward system as it can help to motivate the users. From this study, it is found that a strategy game and building blocks are the types of games that the children preferred. It is hoped that by applying these features in the computer application, we can reduce the usage of smartphones.

\section{Acknowledgements}

The authors would like to thank to the Faculty of Computer and Mathematical Sciences, Universiti Teknologi MARA, Malaysia for the support throughout this research.

\section{References}

Alghamdi, Y. (2016). Negative Effects of Technology on Children of Today.

Cham, S., Algashami, A., Aldhayan, M., McAlaney, J., Phalp, K., Almourad, M. B., \& Ali, R. (2019) Digital Addiction: Negative Life Experiences and Potential for TechnologyAssisted Solutions.

Creswell, J. W., Clark, P. V. L., Gutmann, M. L., \& Hanson, W. E. (2003). Advanced mixed methods research designs. Handbook of mixed methods in social and behavioral research, 209, 240.

Gandolfi, M. (2010). Digital addiction: Mad, bad or simply a reaction? J. Jiang, K. T. Phalp, and R. Ali, "Digital addiction: Gamification for precautionary and recovery requirements," 2015.

Kassiani, K., Evanthia, P., Rafailia-Iro, V., George, A. M., Nikolaos, B., \& Dimitrios, T. (2018). A Study about Internet Addiction of University Students, Journal of Educational and Social Research, 8 (1), 27-32.

Nightingale, R. (2015). extreme-digital-addiction-destroying-kids-lives-around-globe. Retrieved from makeuseof: http://www.makeuseof.com/tag/extreme-digitaladdiction-destroying-kids-lives-around-globe/.

Rugai, J., \& Hamiliton-Ekeke, J. T. (2016). A Review of Digital Addiction: A Call for.

Souligna, S. (2017). A Browser Based Intervention Approach Towards Managing Internet Addiction Disorder (Doctoral dissertation, Auckland University of Technology).

Zochil, M. L. (2015). A Literature Review of Internet Addiction with a Focus on University Students. Journal of the Australian \& New Zealand Student Services Association. 